\title{
Secagem e avaliação do bagaço de cana de açúcar como adsorvente de corantes têxteis presentes em soluções aquosas
}

\section{Drying and evaluation of sugarcane bagasse, as adsorbent of textile dyes present in aqueous solutions}

\author{
Cinthia Sany França Xavier ${ }^{1}$, Fellipe Farias Crispiniano ${ }^{1}$, \\ Ketyla Karla Rodrigues do Nascimento ${ }^{1}$, Marcello Maia de Almeida ${ }^{\text {, }}$, \\ Fernando Fernandes Vieira ${ }^{1}$
}

\footnotetext{
${ }^{1}$ Universidade Estadual da Paraíba, UEPB, Rua Baraúnas, 351, Universitário, CEP: 58429-500, Campina Grande, PB, Brasil. e-mail: cinthiasany@gmail.com, fellipetecinfo@gmail.com, marcellomaia@gmail.com, fernanvieira@gmail.com
}

\begin{abstract}
RESUMO
Um dos grandes problemas ambientais está relacionado ao descarte inadequado dos efluentes gerados pelas indústrias têxteis, uma vez que seus contaminantes causam alterações nas condições naturais do meio onde são descartados. Nesse contexto, os processos de adsorção surgem como uma técnica de tratamento eficaz no que diz respeito ao custo, flexibilidade e facilidade de operação. Nesta pesquisa avaliou-se a secagem do bagaço da cana-de-açúcar nas temperaturas de 60 e $80{ }^{\circ} \mathrm{C}$ bem como seu potencial como adsorvente natural do corante têxtil sintético. Entre os modelos utilizados para descrever a cinética de secagem, o modelo de Page foi o que melhor se ajustou aos dados experimentais, de acordo com o coeficiente de correlação $\left(R^{2}\right)$ e teste $\mathrm{F}$, onde verificou-se que o modelo é estatisticamente significativo e preditivo, já no planejamento fatorial analisou-se a influência da concentração do corante, do tempo de contato e temperatura de secagem do adsorvente nas variáveis respostas quantidade de corante adsorvida $\left(\mathrm{q}_{\mathrm{t}}\right)$ e remoção da concentração do corante (\%red) onde todas as variáveis foram estatisticamente significativas ao intervalo de confiança de $95 \%$ obtendo-se um valor máximo para a quantidade de corante adsorvido de $8,34 \mathrm{mg}^{-\mathrm{g}^{-1}}$ e uma porcentagem de redução de corante de até $83,4 \%$. Portando, conclui-se que o bagaço de cana de açúcar é uma alternativa ao carvão ativado usando comumente nos processos de adsorção.
\end{abstract}

Palavras-chave: Bioadsorvente, adsorção, planejamento experimental

\section{ABSTRACT}

The inappropriate disposal of effluents generated by the textile industries is considered a major environmental problem because their contaminants cause changes in the natural conditions of the environment where they are discarded. In this context, adsorption processes emerge as an effective treatment technique regarding the cost, flexibility and ease of operation. This research evaluated the sugarcane bagasse drying at temperatures between 60 and $80^{\circ} \mathrm{C}$, as well as its potential as a natural adsorbent of synthetic textile dye. Among the models used to describe the drying kinetics, the Page model was the best fit to the experimental data, according to the coefficient of correlation $\left(\mathrm{R}^{2}\right)$ and test $\mathrm{F}$, in which it was verified that the model is statistically significant and predictive. In the factorial design, the influence of dye concentration, contact time and adsorbed drying temperature were analyzed on the responses variables: amount of dyed adsorbed $\left(\mathrm{q}_{\mathrm{t}}\right)$ and removal of dye concentration (\% rem). All variables were statistically significant at a $95 \%$ confidence interval, obtaining a maximum value for adsorbed dye of $8.34 \mathrm{mg} . \mathrm{g}^{-1}$ and a percentage of dye reduction of up to $83.4 \%$. Therefore, it can be concluded that sugarcane bagasse is an alternative to activated carbon, which is commonly used in adsorption processes.

Keywords: Bioadsorber, adsorption, experimental planning 


\section{INTRODUÇÃO}

Os adsorventes são sólidos com elevada porosidade, onde a maior parte de sua área superficial está localizada em seu interior. Esses sólidos devem possuir características de pequena queda de pressão e boa resistência mecânica para suportar o manuseio. Nesse sentido, o carvão ativado tem sido amplamente utilizado na remoção de uma série de substâncias poluidoras de fluidos, no entanto, devido ao seu custo elevado pode tornar o processo de adsorção inviável economicamente com isso, tem-se buscado novos materiais de baixo custo, que possam substituir o carvão ativado [1].

De acordo com ARAÚJO et al. [2], o carvão ativado é um material rico em carbono que pode ser substituído por materiais provenientes de resíduos agroindustriais, por serem provenientes de fontes renováveis com alto teor de carbono e baixo teor de compostos inorgânicos. Esses resíduos além de apresentarem em sua composição um elevado teor de matérias voláteis, característica que permite a adsorção, possuem uma estrutura altamente porosa, são matérias primas renováveis e de baixo custo. Adsorventes alternativos têm sido identificados como atuantes na remoção de corantes de efluentes têxteis devido à sua capacidade de adsorver poluentes, como a casca do abacaxi [3], o mesocarpo do coco verde [4], a casca da laranja [5] e a casca do limão Taiti [6]. Esses resíduos apresentam morfologia porosa, elevado teor de matéria orgânica, grande quantidade de celulose, hemicelulose e lignina, que são biopolímeros ricos em grupos funcionais, como por exemplo, carboxila, hidroxila, carbonila dentre outros, responsáveis pela adsorção, que podem ser facilmente aplicados para remoção de corantes [7].

A cana-de-açúcar, originária da Indonésia e Nova Guiné, é uma gramínea pertencente à família das Poáceas do gênero Saccharum. Compõe-se essencialmente de duas partes: uma subterrânea, constituída pelos rizomas e pelas raízes e, outra, aérea, pelo colmo, folhas e flores [8]. No processamento da cana-de-açúcar, após a moagem, há a geração do bagaço onde parte é queimado para a geração de energia para a própria usina. No entanto, devido a sua composição (50\% celulose, $27 \%$ hemicelulose e $23 \%$ lignina) o bagaço da canade-açúcar tem-se apresentado como um ótimo adsorvente de corante têxteis [8].

Contudo, FIORENTIN et al. [9], aponta que adsorventes oriundos de resíduos agrícolas que possuam elevado teor de umidade requerem a remoção parcial ou total da umidade presente em seus poros, nesse sentido, a passagem de ar forçado pela amostra, denominado se secagem convectiva forçada, pode acelerar o processo de secagem assegurando a qualidade e a estabilidade do produto e diminuindo a atividade biológica e as mudanças químicas e físicas que possam ocorrer durante o processo de armazenamento do material.

O principal objetivo do processo de secagem do bagaço de cana-de-açúcar é remover, significativamente, um líquido volátil dos produtos in natura, reduzindo assim o seu peso, volume e o teor de umidade no material de forma que o tempo de conservação e a vida útil do produto aumente e facilite o seu transporte, manuseio e armazenamento [10].

O tipo de secagem a ser utilizado depende do produto a ser desidratado, da sua constituição química, das características físicas finais desejadas para o produto, das propriedades do ar de secagem, dos limites de temperatura e do meio de transferência de calor adotados em função da sensibilidade dos compostos químicos, de forma a evitar a perda ou a degradação desses compostos [11].

As curvas de secagem analisam a retirada de umidade do produto com relação ao tempo, podendo assim caracterizar a operação em que as mesmas variam com a espécie, variedade, condições ambientais, métodos de preparo pós-colheita, entre outros fatores, visto que as características dos produtos (composição, estrutura e dimensão) e as condições de secagem são muito diversas. Nesse sentido, diversos modelos matemáticos têm sido utilizados para descrever o processo de secagem de produtos agrícolas [12]. Em vista disso, a obtenção das curvas de secagem é realizada retirando-se as amostras em intervalos de tempo pré-determinados a fim de determinar o teor de umidade do material

Os modelos matemáticos são ferramentas utilizadas para estimar o tempo necessário para redução da umidade do produto sob diferentes condições de secagem de forma a auxiliar nas tomadas de decisão e contribuir na melhoria da eficiência do processo [10]. Esses modelos podem ser divididos em empíricos, semiempíricos e teóricos.

Os modelos teóricos levam em consideração apenas a resistência à transferência da água, descrevem a taxa decrescente de secagem de um sólido e consideram como mecanismo principal a difusão baseada na lei Lei de Fick. Os modelos empíricos consistem numa correlação direta entre o teor de umidade e o tempo de secagem, portanto negligenciam a resistência interna à transferência de massa e de calor, o que permite considerar a umidade e a temperatura constantes para todo o material. Já os semiempíricos baseiam-se, geral- 
mente, na lei de resfriamento de Newton aplicada à transferência de massa, presumindo-se que durante o processo de secagem, as condições sejam isotérmicas e que a transferência de umidade se restrinja apenas à superfície do material. Entre os modelos semiempíricos, o modelo de Lewis ou de Newton, o de Page, o Logarítmico e o de Midilli, têm sido amplamente utilizados para a representação da secagem de produtos agrícolas [13].

Segundo RODRIGUES e HENKES [14], a indústria têxtil se destaca dentre as indústrias responsáveis pela geração de rejeitos que em geral não podem ser assimilados pela natureza, causando alterações nas condições naturais do meio onde são descartados, pois além de gerar grandes volumes de efluentes ricos em matéria orgânica e ainda fortemente tingidos pelos corantes que acabam não se fixando as fibras dos tecidos, consomem grandes quantidades de água e de insumos químicos.

Dado o exposto, um dos grandes problemas ambientais enfrentados pelas indústrias têxteis está relacionado ao tratamento e eliminação de seus efluentes pois, os corantes apresentam diferentes grupos funcionais, inclusive anéis aromáticos que são bastante estáveis e de baixa biodegradabilidade, oferecendo riscos à estabilidade dos ecossistemas aquáticos e a saúde pública [15].

O lançamento de substâncias químicas com potencial de toxicidade nos sistemas atribui coloração e acaba afetando o valor estético dos corpos d'água gerando interferência na penetração da luz solar no meio aquático retardando a fotossíntese, inibindo o crescimento da biótica aquática e interferindo na solubilidade de gases em corpos d'água. Além disso, ao longo do tempo, alguns contaminantes vão entrando na cadeia alimentar dos organismos, o que representa um enorme risco à saúde e à biodiversidade [6; 16]

Portanto, a escolha do bagaço de cana-de-açúcar neste trabalho se justifica pelo fato desta biomassa possuir características favoráveis que podem contribuir para este ser um bom adsorvente na remoção de corantes têxteis em efluentes. Assim, a utilização deste material pode ser uma excelente alternativa, como forma de reaproveitamento de resíduos agrícolas gerados.

Nesse contexto, o presente trabalho teve como objetivos estudar e determinar as curvas e o tempo de secagem do bagaço da cana-de-açúcar ajustando modelos matemáticos de secagem aos dados experimentais obtidos na secagem do bagaço, definindo o melhor modelo ajustado de forma a analisar o bioadsorvente produzido, nas temperaturas de 60 e $80^{\circ} \mathrm{C}$, no tratamento de efluentes têxteis.

\section{MATERIAIS E MÉTODOS}

A pesquisa experimental foi realizada nas dependências físicas do Núcleo de Pesquisa em Alimentos (NUPEA) e no Laboratório de Pesquisa em Ciências Ambientais (LAPECA) pertencentes ao Centro de Ciências e Tecnologia (CCT) da Universidade Estadual da Paraíba (UEPB), na cidade de Campina Grande - PB.

O bagaço da cana-de-açúcar utilizado neste trabalho foi adquirido no comércio da cidade de Campina Grande - PB. A coleta do material foi realizada logo após a etapa de moagem da cana de forma que não ocorresse a degradação microbiológica das amostras do bagaço. Foram coletadas $400 \mathrm{~g}$ da biomassa onde a mesma foi cortada em pedaços uniformes de aproximadamente $1,0 \mathrm{~cm}$ de comprimento com o intuito de se ter um material homogêneo durante a secagem. Em seguida, foi realizada sua lavagem por três vezes em um recipiente contendo 4,0L de água destilada para a retirada de possíveis impurezas, de acordo com a Figura 1, e reservada para secagem.

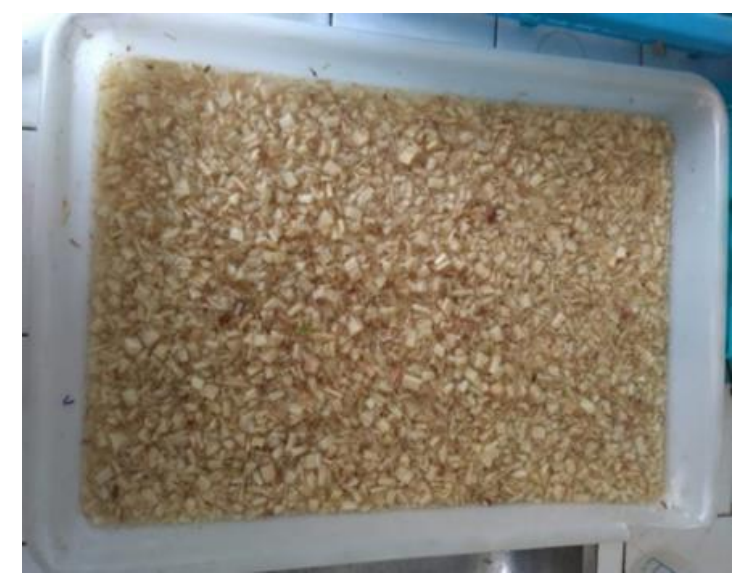

Figura 1: Biomassa durante processo de lavagem 


\subsection{Determinação da umidade inicial}

Para análise da umidade inicial do produto foram pesados $10 \mathrm{~g}$ da biomassa em balança analítica marca Marconi, modelo AL500C na qual foram submetidas à secagem em balança de infravermelho, tal processo foi realizado em triplicata.

\subsection{Estudo da cinética de secagem do adsorvente}

Para construção da curva de secagem utilizaram-se as temperaturas de $60^{\circ} \mathrm{C}$ e $80^{\circ} \mathrm{C}$ com variação de \pm $2,5^{\circ} \mathrm{C}$ e uma massa inicial do bagaço da cana-de-açúcar in natura de aproximadamente $400 \mathrm{~g}$. Foi utilizado uma estufa da marca Marconi, modelo MA 035/3IN250, com circulação de ar forçada até que a biomassa atingisse peso constante. Durante as sete primeiras horas o material foi retirado da estufa em determinados intervalos de tempo, conforme Tabela 1, para realização de pesagem em balança analítica da marca Marconi, modelo AL500C com o objetivo de se determinar o teor de umidade em função do tempo, completas sete horas de experimento, atingiu-se massa constante.

Tabela 1: Intervalo de tempo utilizado para pesagem do material durante a secagem

\begin{tabular}{cc}
\hline TEMPO DE MONITORAMENTO (MIN) & INTERVALO DE PESAGEM (MIN) \\
\hline Primeira hora & A cada $5 \mathrm{~min}$ \\
\hline Segunda hora & A cada $10 \mathrm{~min}$ \\
\hline Terceira hora & A cada $15 \mathrm{~min}$ \\
\hline Quarta à sétima hora & A cada $30 \mathrm{~min}$ \\
\hline
\end{tabular}

Com a coleta desses dados foram construídas as curvas de secagem obtida a partir do gráfico e de taxa de secagem. A umidade em base seca em cada instante foi obtida a partir da Equação 1, onde está representa a quantidade de água por massa seca de material.

$$
U_{\text {base seca }}=\frac{\text { Massa inicial }- \text { Massa final }}{\text { Massa final }}
$$

Em que:

$\mathrm{U}_{\text {base seca }}$ - razão entre a massa de água presente na amostra e a massa de sólido isenta desta umidade, em um determinado tempo;

$\mathrm{M}_{\text {úmida }}$ - massa do bagaço antes de submetida a secagem na estufa $(\mathrm{g})$;

$\mathbf{M}_{\text {seca }}$ - massa seca obtida em estufa (g) após secagem (bagaço seco).

O procedimento foi realizado em triplicata para cada temperatura e em seguida o material foi moído em um moinho de facas modelo MA 048 Marconi Brasil, utilizando telas mesh $20=0,85 \mathrm{~mm}$ e $32=0,5 \mathrm{~mm}$, em aço inox, com a finalidade de se obter um material com granulometria uniforme, como observado na Figura 2, e em seguida, armazenado em potes plásticos e depositados em um recipiente de isopor para controle da umidade. 


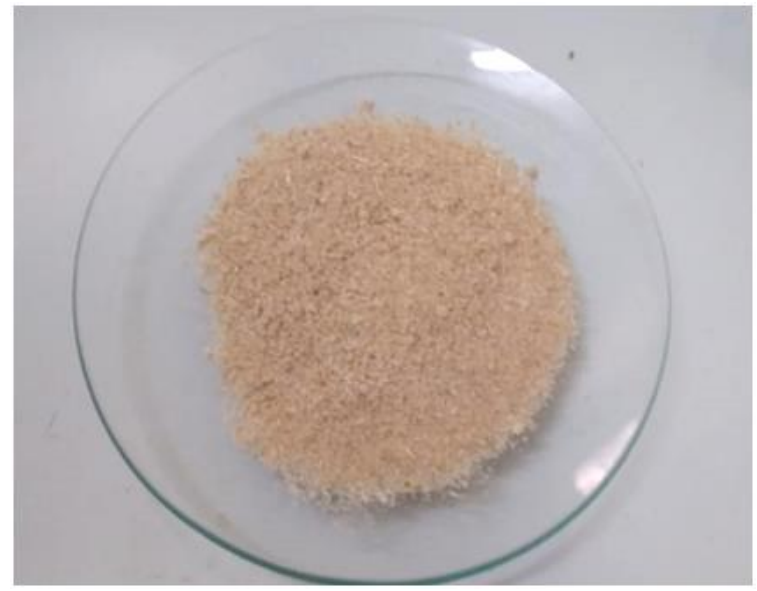

Figura 2: Bagaço da cana-de-açúcar após o processo de secagem e moagem

A cinética de secagem foi caracterizada a partir dos dados do adimensional de umidade (u) em função do tempo do processo. Para a determinação da razão de umidade do bagaço de cana-de-açúcar para as diferentes condições de secagem foi utilizada a Equação 2.

$$
R U=\frac{U-U_{e}}{U_{o}-U_{e}}
$$

Em que:

RU é a razão de umidade (adimensional); U é teor de água médio no tempo t (\% base seca); $\mathrm{U}_{\mathrm{e}}$ é o teor de água de equilíbrio (\% base seca) e $\mathrm{U}_{0}$ é o teor de água inicial (\% base seca).

Para ajustar os dados experimentais foram utilizados os modelos matemáticos de Midilli, Newton, Logarítmico e Page, descritos na Tabela 2.

Tabela 2: Modelos matemáticos mais utilizados na secagem de produtos agrícolas

\begin{tabular}{c|c}
\hline Page [17] & $Y=e^{\left(-k t^{n}\right)}$ \\
\hline Newton O'Callaghan [18] & $Y=e^{(-k t)}$ \\
\hline Logarítmico [19] & $Y=a \cdot e^{(-k t)}+c$ \\
\hline Midilli et al. [20] & $Y=a \cdot e^{\left(-k t^{n}\right)}+b t$ \\
\hline
\end{tabular}

Fonte: adaptada de GRAEBIN et al., 2014 [21]

Em que, Y representa a razão da umidade do produto adimensional, t o tempo de secagem (s), $\mathrm{k}$ a constante de secagem e a, b, c e n os coeficientes dos modelos.

Os critérios de escolha do melhor modelo para os modelos cinéticos foram determinados com base nos maiores valores do coeficiente de determinação $\left(R^{2}\right)$, da análise de variância (Teste $F$ ), e no menor valor da raiz do erro médio (RM).

\subsection{Ensaio de adsorção}

Para avaliar a capacidade de adsorção do adsorbato pelo adsorvente utilizado foi preparado uma solução aquosa, contendo o corante têxtil da marca Tupy® cor bordô $\mathrm{n}^{\circ} 16$, visto que o mesmo não possui venda restrita, sendo de fácil obtenção no comércio e é composto por um corante direto, cloreto de sódio e um tensoativo. O êxito da aplicação dessas substâncias tem sido atribuído a estabilidade diante de algumas variáveis, como luz, $\mathrm{pH}$ e temperatura, além de proverem um maior espectro de cores e serem mais viáveis economicamente. Contudo, durante os processos de tingimento parte dessas substâncias é dispensada na água de descarte, causando o acúmulo nos corpos de águas naturais determinando efeitos tóxicos para a fauna e flora, além de impedir a penetração e difusão da luz e a solubilidade de gases no meio aquático.

Foi pesado 1,0g do corante têxtil, dissolvido em água destilada e aferido o volume para 1,0L, obtendose assim uma solução estoque com uma concentração de $1000 \mathrm{mg} . \mathrm{L}^{-1}$ para posterior utilização. A concentra- 
ção das soluções foi quantificada baseada no Standard Methods for the Examination of Water and Wastewater [22] e para determinar a concentração do corante na amostra foi utilizado o espectrofotômetro de absorção molecular na região do ultravioleta e visível da marca BEL, modelo Spectrophotometer SP 2000 UV. Inicialmente, realizou-se uma varredura no espectrofotômetro a fim de se determinar o comprimento de onda no qual o composto a ser quantificado absorve a máxima radiação, sendo 520nm o comprimento que apresentou maior absorção. Em seguida, uma curva de calibração para o corante foi construída utilizando concentrações do corante entre 0 e $100 \mathrm{mg} . \mathrm{L}^{-1}$.

Para determinar a influência dos seguintes fatores: temperatura da secagem do bagaço de cana-deaçúcar in natura, concentração do corante e tempo de contato entre o adsorvente e o adsorbato, empregou-se um planejamento fatorial do tipo $2^{3}$, realizado em triplicata, totalizando 24 amostras. Os experimentos de adsorção foram realizados em frascos de Erlenmeyers de $125 \mathrm{~mL}$ contendo $25 \mathrm{~mL}$ da solução aquosa em $\mathrm{pH} 7$ $\pm 0,5$ e $0,25 \mathrm{~g}$ do adsorvente, já as variáveis independentes utilizadas no presente trabalho são apresentadas da Tabela 3 com valores codificados e reais.

Tabela 3: Valores das variáveis independentes (temperatura, concentração e tempo)

\begin{tabular}{lll}
\hline PONTOS & $(-1)$ & $(1)$ \\
\hline Temperatura $\left({ }^{\circ} \mathrm{C}\right)$ & 60 & 80 \\
\hline Concentração $\left(\mathrm{mg} \cdot \mathrm{L}^{-1}\right)$ & 50 & 100 \\
\hline Tempo $(\mathrm{min})$ & 30 & 60 \\
\hline
\end{tabular}

Os ensaios foram mantidos sob agitação de $120 \mathrm{rpm}$ em temperatura ambiente. Após o tempo de contato estabelecido, as amostras foram filtradas e em seguida separadas por centrifugação com uma rotação de 2500rpm pelo período de 30min, as concentrações do corante nas soluções foram determinadas por espectrofotometria UV-VIS. A porcentagem de redução do corante e a quantidade de corante adsorvida por massa de adsorvente utilizada foram calculadas pela Equação 3 e Equação 4, respectivamente.

$$
\begin{gathered}
\text { \%red }=\frac{C_{o}-C_{t}}{C_{o}} \cdot 100 \% \\
q_{t}=\frac{V \cdot\left(C_{o}-C_{t}\right)}{m}
\end{gathered}
$$

Em que, \%red é a porcentagem de redução da concentração do corante (\%), $\mathrm{q}_{\mathrm{t}}$ a quantidade de corante adsorvido pelo bagaço $\left(\mathrm{mg} . \mathrm{g}^{-1}\right), \mathrm{C}_{\mathrm{o}}$ a concentração inicial do corante $\left(\mathrm{g} . \mathrm{L}^{-1}\right), \mathrm{C}_{\mathrm{t}}$ a concentração do corante em um instante de tempo t $\left(\mathrm{g} . \mathrm{L}^{-1}\right)$, $\mathrm{m}$ a massa do adsorvente em base seca $(\mathrm{g})$; e $\mathrm{V}$ o volume da solução do corante $(\mathrm{L})$.

A estimativa dos parâmetros dos modelos cinéticos bem como influência das variáveis independentes foi analisada com o auxílio do software STATISTICA, disponibilizado pelo Programa de Pós-graduação em Ciência e Tecnologia Ambiental (PPGCTA/UEPB).

\section{RESULTADOS E DISCUSSÃO}

\subsection{Cinética de secagem do bagaço de cana-de-açúcar}

Para construção da umidade adimensional em função do tempo dos experimentos de bagaço de cana-deaçúcar em estufa com recirculação de ar nas temperaturas de 60 e $80{ }^{\circ} \mathrm{C}$, foram utilizadas as medidas de umidade em base seca obtidas para as amostras retiradas em diferentes intervalos de tempo, onde observou-se que na temperatura de $80^{\circ} \mathrm{C}$ houve um maior decaimento da umidade na fase inicial do processo, onde a média da umidade adimensional no tempo de $300 \mathrm{~min}$ para a temperatura de $60^{\circ} \mathrm{C}$ foi de 0,0501 , enquanto que para temperatura de $80^{\circ} \mathrm{C}$ foi de 0,0002 comprovando assim que o processo de secagem ocorre de forma mais rápida no segundo caso

No que diz respeito a umidade inicial do bagaço de cana-de-açúcar concluiu-se que a água contida na matéria-prima lavada representa cerca de $90,97 \%$ de sua massa total. Com relação a avaliação dos modelos 
de secagem os dados experimentais da cinética de secagem a 60 e $80{ }^{\circ} \mathrm{C}$ foram ajustados aos modelos empíricos de Midilli, Newton, Logarítmico e Page, como pode ser observado nas Figuras 3 e 4, respectivamente.

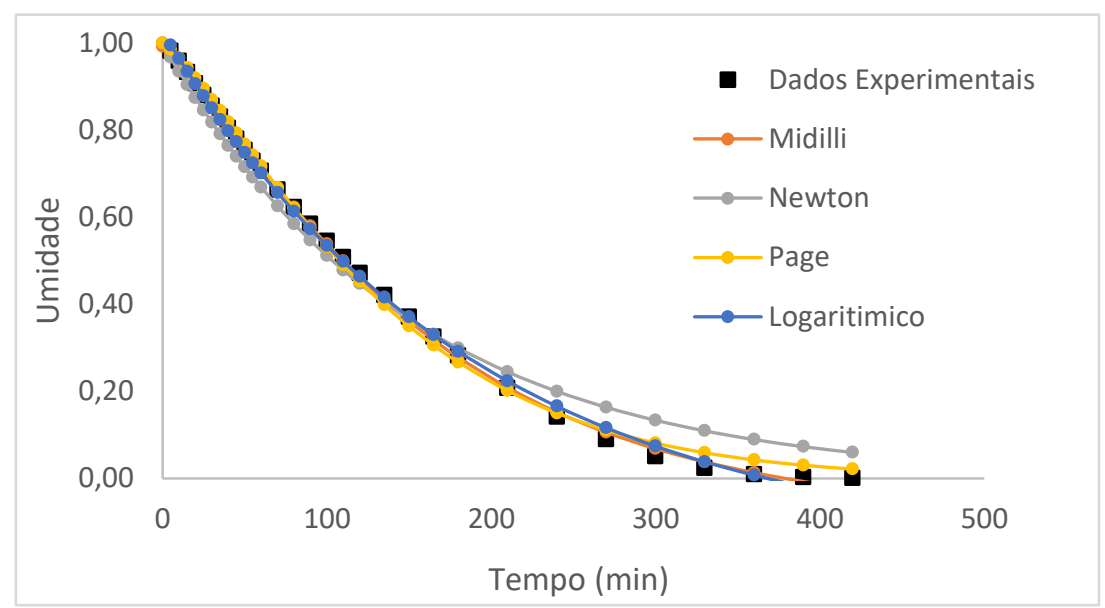

Figura 3: Modelos ajustados aos dados de secagem do bagaço da cana-de-açúcar na temperatura de $60{ }^{\circ} \mathrm{C}$

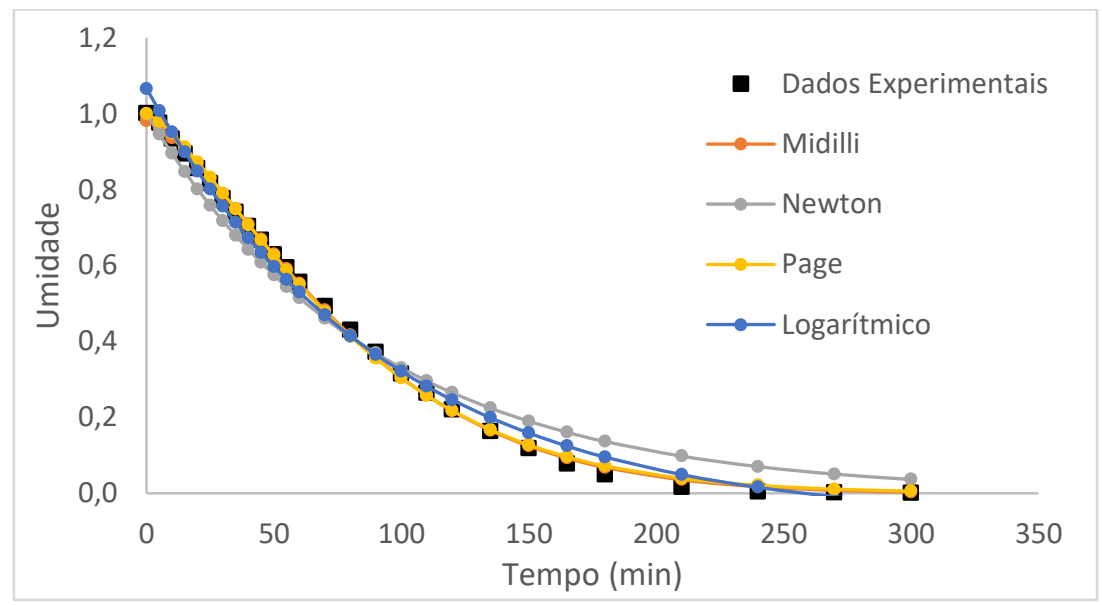

Figura 4: Modelos ajustados aos dados de secagem do bagaço da cana-de-açúcar na temperatura de $80{ }^{\circ} \mathrm{C}$

GRAEBIN et al. [21] estudou a secagem do bagaço de cana-de-açúcar em estufa com circulação forçada de ar nas temperaturas de $60,70,80,90$ e $100^{\circ} \mathrm{C}$ e verificou que o aumento no parâmetro temperatura promove uma diminuição no tempo de secagem. Os dados cinéticos experimentais de secagem do bagaço foram ajustados aos modelos matemáticos de Page, Newton e Placa Plana onde observou-se que para todas as temperaturas o modelo de Page obteve o melhor ajuste.

GOYALDE et al. [23] realizou a secagem da cana-de-açúcar nas temperaturas de 50 e $60^{\circ} \mathrm{C}$ e ajustou os dados experimentais aos modelos de Midilli, Henderson e Pabis, Logarítmico e Page, onde o modelo de Midilli foi o que melhor se ajustou aos dados de secagem da cana-de-açúcar picada.

Na Tabela 4 encontram-se os parâmetros obtidos a partir dos resultados experimentais ajustados para cada um dos modelos utilizados. 
Tabela 4: Comparação dos parâmetros dos modelos de secagem do bagaço da cana-de-açúcar com os dados da média obtida nos experimentos realizados a 60 e $80^{\circ} \mathrm{C}$

\begin{tabular}{ccccccc}
\hline TEMPERATURA & MODELO & $\mathbf{A}(\mathbf{A D M})$ & $\mathbf{K}\left(\mathbf{M I N}^{-1}\right)$ & $\mathbf{N}(\mathbf{A D M})$ & $\mathbf{B}\left(\mathbf{M I N}^{-1}\right)$ & $\mathbf{C}(\mathbf{A D M})$ \\
\hline \multirow{3}{*}{$\mathbf{6 0}^{\mathbf{0}} \mathbf{C}$} & Midilli & 0,9922 & 0,0023 & 1,1900 & $-1,467 \times 10^{-4}$ & - \\
& Page & - & 0.0019 & 1,2553 & - & - \\
\cline { 2 - 7 } & Newton & - & 0,0067 & - & - & - \\
\cline { 2 - 7 } & Logarítmico & 1,1971 & 0,0052 & - & - & $-0,1708$ \\
\hline \multirow{2}{*}{$\mathbf{8 0}^{\mathbf{}} \mathbf{C}$} & Midilli & 0,9850 & 0,0021 & 1,3600 & $-7,279 \times 10^{-5}$ & - \\
& Page & - & 0,0024 & 1,3477 & - & - \\
& Newton & - & 0,0110 & - & - & - \\
\cline { 2 - 7 } & Logarítmico & 1,1755 & 0,0096 & - & - & $-0,1205$
\end{tabular}

A análise de variância dos modelos a partir do ajuste das equações matemáticas por regressão não linear aos dados de cinética de secagem do bagaço de cana-de-açúcar e o coeficiente de determinação $\left(\mathrm{R}^{2}\right)$ com nível significância de $5 \%$ podem ser observadas nas Tabelas 5 e 6.

Tabela 5: ANOVA e coeficiente de determinação dos modelos de Midilli, Page, Newton e Logarítmico para a secagem do bagaço da cana-de-açúcar em estufa de recirculação de ar à $60^{\circ} \mathrm{C}$

\begin{tabular}{|c|c|c|c|c|c|c|}
\hline & FONTE & $\begin{array}{c}\text { SOMA DOS } \\
\text { QUADRADOS }\end{array}$ & $\begin{array}{l}\text { GRAUS DE } \\
\text { LIBERDADE }\end{array}$ & $\begin{array}{l}\text { MÉDIA DOS } \\
\text { QUADRADOS }\end{array}$ & TESTE F & $\mathbf{R}^{2}$ \\
\hline \multirow{3}{*}{ Midilli } & Regressão & 12,1429 & 4 & 3,0357 & 4395,95 & \multirow{3}{*}{0,9980} \\
\hline & Residual & 0,0071 & 28 & 0,0002 & - & \\
\hline & Total & 12,1500 & 32 & - & - & \\
\hline \multirow{3}{*}{ Page } & Regressão & 12,14052 & 2 & 6,070262 & 5764,75 & \multirow{3}{*}{0,9974} \\
\hline & Residual & 0,00954 & 30 & 0,000318 & - & \\
\hline & Total & 12,15007 & 32 & - & - & \\
\hline \multirow{3}{*}{ Newton } & Regressão & 12,0885 & 1 & 12,0885 & 1460,30 & \multirow{3}{*}{0,9833} \\
\hline & Residual & 0,0615 & 31 & 0,0019 & - & \\
\hline & Total & 12,1500 & 32 & - & - & \\
\hline \multirow{3}{*}{ Logarítmico } & Regressão & 12,1297 & 3 & 4,0432 & 1965,46 & \multirow{3}{*}{0,9945} \\
\hline & Residual & 0,0203 & 29 & 0,0007 & - & \\
\hline & Total & 12,1500 & 32 & - & - & \\
\hline
\end{tabular}

Tabela 6: ANOVA e coeficiente de determinação dos modelos de Midilli, Page, Newton e Logarítmico para a secagem do bagaço da cana-de-açúcar em estufa de recirculação de ar à $80^{\circ} \mathrm{C}$

\begin{tabular}{|c|c|c|c|c|c|c|}
\hline & FONTE & $\begin{array}{l}\text { SOMA DOS } \\
\text { QUADRADOS }\end{array}$ & $\begin{array}{l}\text { GRAUS DE } \\
\text { LIBERDADE }\end{array}$ & $\begin{array}{l}\text { MÉDIA DOS } \\
\text { QUADRADOS }\end{array}$ & TESTE F & $\mathbf{R}^{2}$ \\
\hline \multirow{3}{*}{ Midilli } & Regressão & 8,9966 & 4 & 2,2491 & 6128,38 & \multirow{3}{*}{0,9990} \\
\hline & Residual & 0,0031 & 24 & 0,0001 & - & \\
\hline & Total & 8,9997 & 28 & - & - & \\
\hline \multirow{3}{*}{ Page } & Regressão & 8,9955 & 2 & 4,4977 & 8125,32 & \multirow{3}{*}{0,9986} \\
\hline & Residual & 0,0042 & 26 & 0,0001 & - & \\
\hline & Total & 8,9997 & 28 & - & - & \\
\hline \multirow{3}{*}{ Newton } & Regressão & 8,9239 & 1 & 8,9239 & 754,54 & \multirow{3}{*}{0,9768} \\
\hline & Residual & 0,0758 & 27 & 0,0028 & - & \\
\hline & Total & 8,9997 & 28 & - & - & \\
\hline \multirow{3}{*}{ Logarítmico } & Regressão & 8,9711 & 3 & 2,9903 & 872,72 & \multirow{3}{*}{0,9912} \\
\hline & Residual & 0,0286 & 25 & 0,0011 & - & \\
\hline & Total & 8,9997 & 28 & - & - & \\
\hline
\end{tabular}


O modelo de Newton se restringe a secagem em temperatura constante, onde durante o processo de secagem de materiais higroscópicos porosos no período de taxa de secagem decrescente, a mudança da umidade é proporcional à diferença instantânea entre o teor de umidade do material e o teor de umidade do material, quando em condições de equilíbrio com o ar de secagem [18], enquanto que o modelo Logarítmico de secagem descreve de forma aceitável os fenômenos de transferência de calor e massa durante a secagem de uma camada delgada de determinado produto capilar poroso, no entanto, BROOKER et al. [24] afirmam que esse modelo simula de forma pouco satisfatória a curva de secagem, visto que, o modelo prediz valores muito reduzidos para a taxa inicial de secagem e que o valor limite, ou seja, o teor de água de equilíbrio, é alcançado muito rapidamente, o que não condiz com as observações experimentais. Já o modelo de Page descrever a secagem de materiais em camada fina em que n representa um parâmetro adimensional de secagem. Bruce [25] afirma que o modelo proposto por Page descreve melhor o processo de secagem de produtos agrícolas que o modelo exponencial.

Todos os modelos analisados apresentaram uma boa concordância com os dados experimentais, no entanto, os modelos Page e Midilli apresentaram melhores resultados segundo critérios estatísticos $\mathrm{R}^{2}$ tanto para a temperatura de $60{ }^{\circ} \mathrm{C}$ quanto para a de $80{ }^{\circ} \mathrm{C}$. No entanto, o coeficiente de determinação $\left(\mathrm{R}^{2}\right)$ não constitui sozinho um bom critério para seleção de modelos não lineares portanto, de acordo com o teste $\mathrm{F}$, o modelo de Page foi o que melhor se ajustou aos dados de secagem do bagaço de cana-de-açúcar.

Segundo NETO et al. [26], um modelo pode ser considerado estatisticamente significativo se Fcal > Ftab e preditivo se essa relação for superior a 10. Observa-se que a razão entre Fcal e o Ftab foi superior a 10 confirmando que para um nível de confiabilidade de $95 \%$ os modelos utilizados são estatisticamente significativos e preditivos para representar a secagem do bagaço da cana-de-açúcar em estufa de recirculação de ar e a porcentagem de variação explicada pelos modelos $\left(\mathrm{R}^{2}\right)$ é considerada muito satisfatória, acima de $99,7 \%$, para ambas as temperaturas.

\subsection{Estudo da adsorção}

O planejamento fatorial $2^{3}$ desenvolvidos em triplicata teve como variáveis resposta a quantidade de corante adsorvida por massa de adsorvente utilizada $\left(\mathrm{q}_{\mathrm{t}}\right)$ e a redução de corante pós adsorção (\%red).

A influência das variáveis independentes (temperatura, concentração e tempo) nas variáveis respostas $\left(\mathrm{q}_{\mathrm{t}}\right)$ e (\%red) está representada pelo diagrama de Pareto nas Figuras 5 e 6.

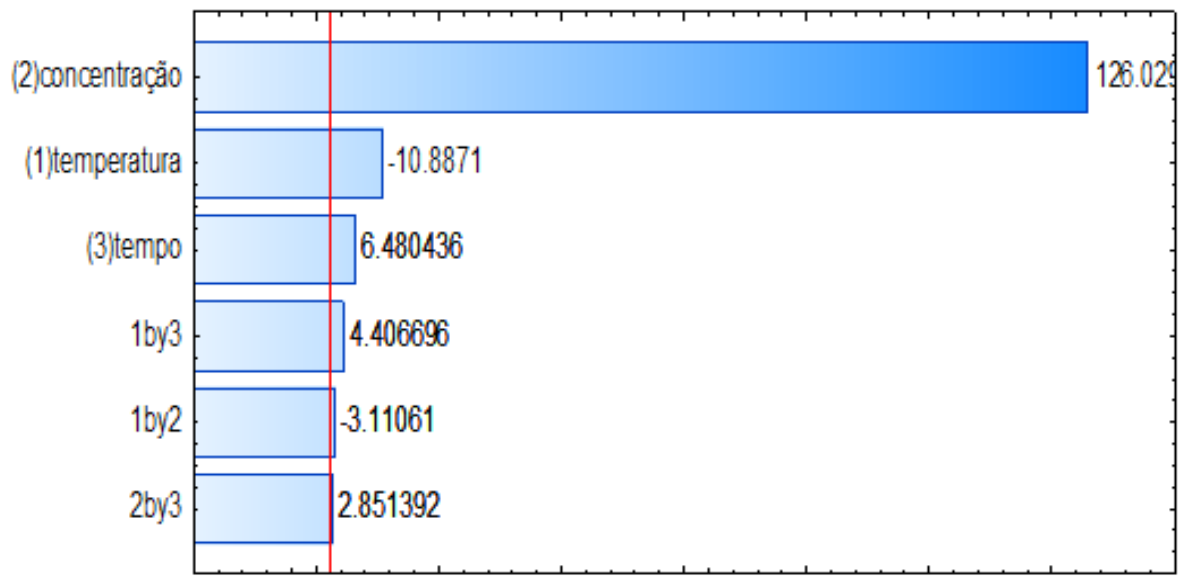

Figura 5: Diagrama de Pareto - efeitos para quantidade de corante adsorvida $\left(\mathrm{q}_{\mathrm{t}}\right)$. 


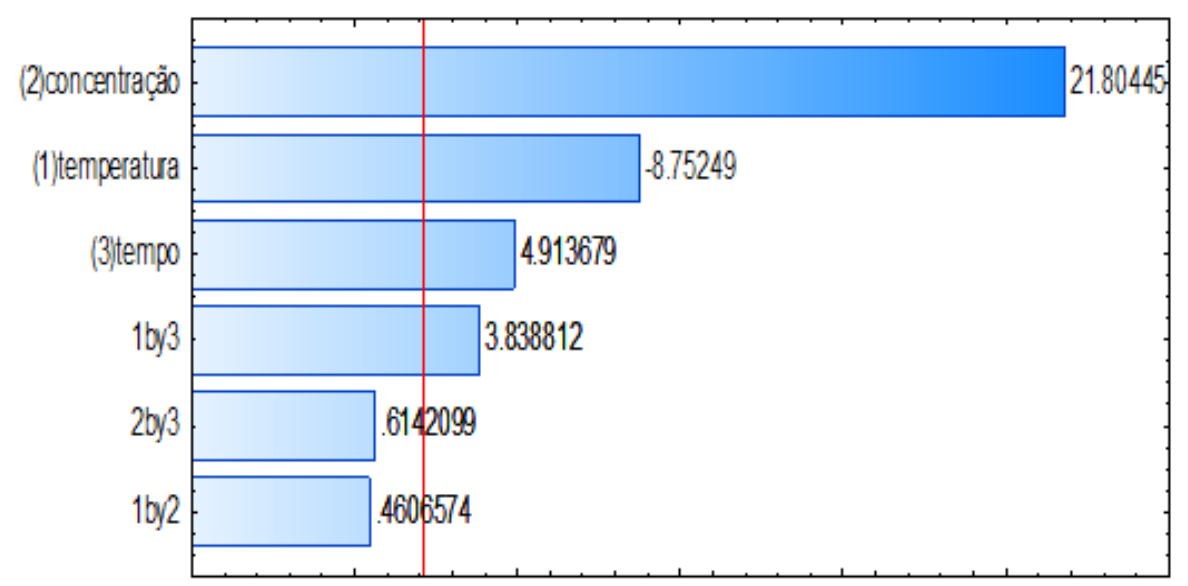

Figura 6: Gráfico de Pareto - efeitos para redução do corante (\%red).

Analisando as Figuras 5 e 6 pode-se inferir que a concentração do corante foi a variável mais importante no processo de adsorção do corante Tupy® cor bordô, tanto para a variável $\mathrm{q}_{\mathrm{t}}$ quanto para a \%red, exercendo efeito positivo em ambos os casos. Além disso, observa-se que para o caso da variável resposta $\mathrm{q}_{\mathrm{t}}$ todas as variáveis independentes e suas interações são estatisticamente significativas ao intervalo de confiança de 95\%. Já para a variável resposta porcentagem de remoção as interações concentração-tempo e temperaturaconcentração não apresentaram relevância do ponto de vista estatístico para o planejamento utilizado.

$\mathrm{O}$ valor do efeito principal temperatura tanto com relação à quantidade de corante adsorvida quanto com relação a porcentagem de redução de corante foi negativo, ou seja, a medida em que a temperatura aumentou de 60 para $80^{\circ} \mathrm{C}$ a resposta da quantidade adsorvida e a \%red diminuíram. Já as variáveis concentração e tempo apresentaram efeito positivo, implicando dizer que a medida que há o aumento dessas variáveis ocorrerá uma maior quantidade de corante adsorvido e maior redução de corante do meio. Nos gráficos de contornos indicados na Figura 7 verificamos a influência das variáveis temperatura-concentração e concentraçãotempo na variável resposta $\mathrm{q}_{\mathrm{t}}$. Na Figura 7(a), temos a relação entre temperatura e concentração, onde a medida em que diminui-se a temperatura e aumenta-se a concentração a quantidade de corante adsorvido aumenta, já a Figura 7(b) relaciona concentração e tempo onde com o aumento de ambas variáveis tem-se um maior valor para $\mathrm{q}_{\mathrm{t}}$, confirmando assim os resultados obtidos no diagrama de Pareto da Figura 5.
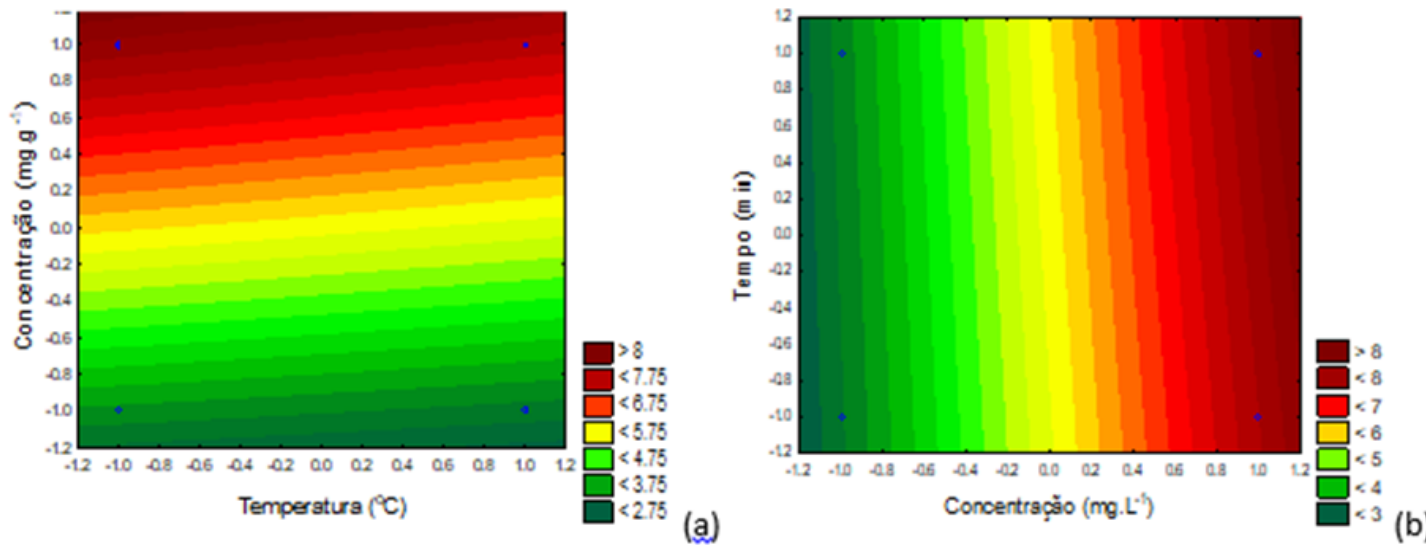

Figura 7: Gráficos de contorno para a variável resposta qt analisando as interações entre as variáveis independentes: (a) temperatura e concentração; (b) concentração e tempo

Em concordância com o diagrama de Pareto da Figura 6 os gráficos de contorno para a remoção da concentração do corante podem ser visualizados na Figura 8, onde nota-se que na Figura 8(a) para obtenção de maiores reduções de concentração de corante faz-se necessário a diminuição da temperatura e o aumento da concentração já a Figura 8(b) indica que a medida que aumenta-se a concentração e o tempo de contato temse uma maior quantidade de corante removido, onde esta condição dá-se devido à saturação da solução de corante que facilita o processo de adsorção. 

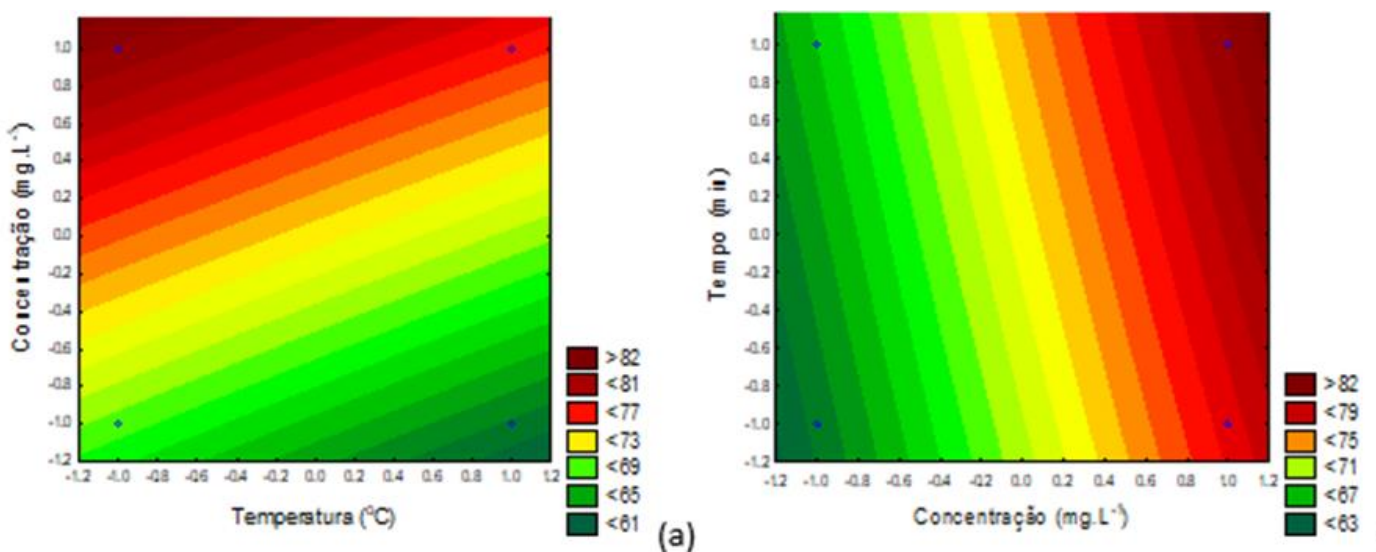

(a)

(b)

Figura 8: Gráficos de contorno para a variável resposta \%red analisando as interações entre as variáveis independentes: (a) temperatura e concentração e (b) concentração e tempo

Devido a pequena variação da capacidade de adsorção entre as temperaturas analisadas, realizou-se um teste de comparação de duas variâncias (Teste F), com o objetivo de confirmar a melhor temperatura de secagem do adsorvente.

Na Tabela 7 são apresentados os parâmetros da análise de variância para os ajustes do modelo tendo como variáveis dependentes a quantidade de corante adsorvida e o percentual de redução de corante, respectivamente, podendo verificar se o modelo proposto é significativo, preditivo ou se apresenta falta de ajuste.

Tabela 7: ANOVA e coeficiente de determinação do planejamento fatorial tendo como variável dependente o $\mathrm{q}_{\mathrm{t}} \mathrm{e}$ a \%red

\begin{tabular}{|c|c|c|c|c|c|c|}
\hline & FONTE & $\begin{array}{l}\text { SOMA DOS } \\
\text { QUADRADOS }\end{array}$ & $\begin{array}{l}\text { GRAUS DE } \\
\text { LIBERDADE }\end{array}$ & $\begin{array}{l}\text { MÉDIA DOS } \\
\text { QUADRADOS }\end{array}$ & FCAL/FTAB & $\mathbf{R}^{2}$ \\
\hline \multirow{3}{*}{$\mathbf{q}_{\mathbf{t}}$} & Regressão & 130,64 & 6 & 21,7745 & 685,84 & \multirow{3}{*}{0,998} \\
\hline & Resíduo & 0,1381 & 17 & 0,0081 & - & \\
\hline & Total & 130,78 & 23 & - & - & \\
\hline \multirow{3}{*}{$\%$ red } & Regressão & 130,64 & 6 & 21,7745 & 685,84 & \multirow{3}{*}{0,998} \\
\hline & Resíduo & 0,1381 & 17 & 0,0081 & - & \\
\hline & Total & 130,78 & 23 & - & - & \\
\hline
\end{tabular}

Comparando os valores de $\mathrm{F}_{\text {calculado }}$ e $\mathrm{F}_{\text {tabelado }}$ verifica-se que os modelos para respostas de $\mathrm{q}_{\mathrm{t}} \mathrm{e}$ \% Red são estatisticamente significativos e preditivos, pois a razão $F_{\text {calculado }}$ por $F_{\text {tabelado }}$ para regressão está acima de 10 , em ambos os casos, ao nível de confiança de 95\%. Portanto, o modelo proposto é válido para o processo de adsorção de corantes têxteis.

Nas Equações 5 e 6 apresentamos os modelos matemáticos que simulam a influência das variáveis independentes na quantidade adsorvida e na porcentagem de remoção de corante, respectivamente. Os valores destes fatores são codificados de acordo com o planejamento experimental.

$$
\begin{aligned}
& q_{t}=5,6-0,2 X_{1}+2,318 X_{2}+0,119 X_{3}-0,057 X_{1} X_{2}+0,081 X_{1} X_{3}+0,052 X_{2} X_{3} \\
& \% \text { red }=72,433-2,718 X_{1}+6,772 X_{2}+1,526 X_{3}+1,192 X_{2} X_{3}
\end{aligned}
$$

Em que,

$\mathrm{X}_{1}$ - Temperatura;

$\mathrm{X}_{2}$ - Concentração;

$\mathrm{X}_{3}$ - Tempo. 


\section{CONCLUSÕES}

$\mathrm{Na}$ avaliação do potencial do bagaço da cana-de-açúcar como bioadsorvente para remoção do corante comercial Tupy® utilizando o processo de adsorção foi possível verificar que a secagem é fortemente influenciada pela temperatura e que a cinética de secagem é acelerada em temperaturas mais elevadas. Foi possível ajustar os modelos cinéticos de secagem aos dados experimentais de secagem do bagaço de cana-deaçúcar, sendo o modelo de Page o que melhor representou o processo de secagem segundo critérios estatísticos Teste $\mathrm{F}$, para as temperaturas de 60 e $80^{\circ} \mathrm{C}$.

Nos testes de adsorção o planejamento fatorial $2^{3}$ teve como objetivo verificar a influência da temperatura de secagem do adsorvente, da concentração do corante e do tempo de contato entre adsorvente e adsorbato na variável resposta quantidade de corante adsorvida $\left(\mathrm{q}_{t}\right)$ e redução de concentração do corante (\%red), onde todas as variáveis foram estatisticamente significativas ao intervalo de confiança de $95 \%$. Verificou-se que para melhores resultados de $\mathrm{q}_{\mathrm{t}} \mathrm{e}$ de porcentagem de redução de corante o planejamento apontou que maiores concentrações do corante e tempo de contato e menores valores de temperatura tornam o processo de adsorção mais eficiente, obtendo-se um valor máximo para a quantidade de corante adsorvido de $8,34 \mathrm{mg} \cdot \mathrm{g}^{-1}$ e uma porcentagem de redução de corante de até $83,4 \%$.

De onde conclui-se que o bagaço de cana de açúcar é um bioadsorvente promissor para adsorção de corantes têxteis em soluções aquosas.

\section{AGRADECIMENTOS}

Ao CNPq pela concessão da bolsa.

\section{BIBLIOGRAFIA}

[1] BERTACCO, T.C., CERON, L.P., LIKS, L.A.S. Verificação da capacidade de adsorção da cinza da casca de arroz em efluente de cromo hexavalente em fluxo contínuo. Engevista, v. 21, n.1, pp.114-125, 2019.

[2] ARAUJO, L.S., COUTINHO, A.R., MENDEZ, M.O.A., et al., Caracterização e avaliação de fatores que determinam a remoção de microcistina-LR em carvão ativado granular produzido a partir de diferentes matérias-primas. Engenharia Sanitária Ambiental. Rio de Janeiro, v. 23, n. 6, pp. 1131-1142, 2018.

[3] ANTUNES, E.C.E.S., PEREIRA, J.E.S., MEDEIROS, M.F.D., et al., Remoção de corante têxtil utilizando a casca do abacaxi como adsorvente natural. Holos Environment, v. 03, n. 34, 2018.

[4] OLIVEIRA, F.M., COELHO, L.M., MELO, E.I.. Avaliação de processo adsortivo utilizando mesocarpo de coco verde para remoção do corante azul de metileno. Rio de Janeiro, v. 23, n. 04, 2018.

[5] NASCIMENTO, K.K.R., VIEIRA, F.F., ALMEIDA, M.M., et al., Aproveitamento da casca de laranja Pêra como adsorvente no tratamento de efluentes têxteis. Revista brasileira de Engenharia Agrícola e Ambiental, v. 23, n. 9, pp.716-722, 2019.

[6] COSTA, D.M.A., MELO, J.J.S. Estudo da capacidade de remoção de azul de metileno pela biomassa da casca do limão taiti (citus latifolia). Holos Environment, v. 18, n. 2, 2018.

[7] NASCIMENTO, R.F., LIMA, A.C.A., VIDAL, C.B., et al., Adsorção: aspectos teóricos e aplicações ambientais. Fortaleza: Imprensa Universitária, 2014.

[8] MENDES, F.M., HEIKKILÄ, E., FONSECA, M.B., et al., Topochemical characterization of sugar cane pretreated with alkaline sulfite. Industrial Crops and Products (Print), v. 69, pp. 60-67, 2015.

[9] FIORENTIN, L.D., MENON, B.T., ALVES, J.A., et al., Análise da secagem do bagaço de laranja em camada fina utilizando modelos semi-teóricos e empíricos. Engevista, v.14, n.1, pp.22-33, 2012.

[10] CARVALHO J.M.G., BUENO, S.G.S., OLIVEIRA, D.E.C., et al., Modelagem matemática e propriedades termodinâmicas da secagem do grão de girassol. Global Science and Technology, Rio Verde, v.11, n.02, pp.136-149, 2018.

[11] FIORENTIN, L.D., MENON, B.T., ALVES, J. A., et al., Determinação da cinética e das isotermas de secagem do bagaço da laranja. Acta Scientiarum Technology, v. 32, n. 2, pp. 147-152, 2010.

[12] BOTELHO, F.M., HAUTH, M.R., HOSCHER, R.H., et al., Modelagem matemática da contração volumétrica de grãos de soja durante o processo de secagem. Revista Engenharia na Agricultura v. 26, n. 01, pp.1-12, 2018

[13] SIQUEIRA, V.C., RESENDE, O., CHAVES, T.H. Mathematical modelling of the drying of jatropha fruit: an empirical comparison. Revista Ciência Agronômica, v. 44, n. 2, pp. 278-285, 2013. 
[14] RODRIGUES, L.S., HENKES, J. A. Gerenciamento de resíduos sólidos em uma indústria têxtil. R. gestão \& sustentabilidade ambiental, Florianopolis, v. 7, n. 1, pp. 700-744, 2018.

[15] HOLANDA, C.A., SOUZA, J.L., SANTOS, C.C., et al., Remoção do Corante Têxtil Turquesa de Remazol Empregando Aguapé (Eichhornia crassipes) como Adsorvente. Orbital: The Electronic Journal of Chemistry, v.7, n.2, pp.141-154, 2015.

[16] ALMAGUER, M.A., CARPIO, R.R., ALVES, T.L.M., et al., Experimental study and kinetic modelling of the enzymatic degradation of the azo dye Crystal Ponceau 6R by turnip (Brassica rapa) peroxidase. Journal Environmental Chemical Engineering, v. 6, pp. 610-615, 2018.

[17] PAGE, G.E. Factors influencing the maximum rates of air-drying shelled corn in thin layer. Thesis (Master of Science) - Purdue University, 1949.

[18] O’CALLAGHAN, J.R., MENZIES, D.J., BAILEY, P.H. Digital simulation of agricultural dryer performance. Journal of Agricultural Engineering Research, v.16, n.3, pp. 223-244. 1971.

[19] YALDIZ, O., ERTEKIN, C., UZUN, H.I. Mathematical modeling of thin- layer solar drying of sultana grapes. Energy, v. 26, pp. 457-465, 2001.

[20] MIDILLI, A., KUCUK, H., YAPAR, Z.A. New model for single-layer drying. Drying Technology, v.20, pp.1503-1513, 2002.

[21] GRAEBIN, G.O., VEIT, M.T., SILVA, G.M.C., et al., Utilização do Bagaço de Cana-de-açúcar como material adsorvente do metal níquel. In: Encontro Brasileiro de Adsorção - EBA, Guarujá - SP. X Encontro Brasileiro sobre Adsorção, 2014.

[22] APHA. Standard Methods for the Examination of Water and Wastewater. Washington: American Public Health Association, 1995.

[23] GOYALDE, N.A., MELO, E.C., ROCHA, R.P., et al., Mathematical modeling of the drying kinetics of sugarcane slices. Revista Brasileira de Produtos Agroindustriais, v. 11, n. 2, pp.117-121, 2009.

[24] BROOKER, D.B., BAKKER-ARKEMA, F.W., HALL, C.W. Drying and storage of grains and oilseeds. New York: Van Nostrand Reinhold, 1992. 450p

[25] BRUCE, D.M. Exposed-layer barley drying: Three models fitted to new data up to $150{ }^{\circ} \mathrm{C}$. Journal of Agricultural Engineering Research, London, v.32, n.4, pp.337-347, 1985.

[26] NETO, B.B., SCARMINIO, I.S., BRUNS, R.E. Como fazer experimentos: pesquisa e desenvolvimento na ciência e na indústria. Campinas: Unicamp, 2001, 401p

\section{ORCID}

Cinthia Sany França Xavier

Fellipe Farias Crispiniano

Ketyla Karla Rodrigues do Nascimento

Marcello Maia de Almeida

Fernando Fernandes Vieira https://orcid.org/0000-0002-4840-2653

https://orcid.org/0000-0003-1927-0740

https://orcid.org/0000-0001-6751-5744

https://orcid.org/0000-0001-7889-126X

https://orcid.org/0000-0002-1823-6236 